\title{
A ÉTICA PROFISSIONAL E A ÉTICA DO PROFISSIONAL
}

\section{PROFESSIONAL ETHICS AND PROFESSIONAL'S ETHICS}

\author{
Leandro de Araújo Sardeiro*
}

Recebido: 08/2017

Aprovado: 10/2017

\begin{abstract}
Resumo: O presente ensaio pretende problematizar os aspectos mais gerais da discussão sobre a Ética profissional em geral, de modo a evidenciar as implicações subjetivas que ela implica.

Palavras-chave: Vivência ética; Agir humano; Comunidade profissional.
\end{abstract}

\begin{abstract}
This essay aims to problematize the general aspects of the discussion about professional ethics in general, in order to highlight the subjective implications that it implies.

Keywords: Ethical experience; Acting human; Professional community.
\end{abstract}

Da forma como costuma ser apresentada nos discursos públicos e no próprio senso comum das comunidades de profissionais, a Ética profissional não nos deixa perceber o imenso vazio que a acompanha e o prejuízo que tal vazio ocasiona a uma compreensão mais aprofundada das responsabilidades de um profissional, independente da sua área de atuação. A todos os que leem um "Código de Ética" qualquer, surge de imediato a pergunta sobre o porquê de se tratar de um "Código de Ética". O simples fato de aquele conjunto de normas ter por conteúdo a forma adequada de comportamento de um profissional de uma área pode até ser utilizado para justificar essa inquietação. Isso, contudo, não chega a evidenciar a grandeza da responsabilidade de um profissional enquanto profissional, assim como o Estatuto do Idoso - por si só, enquanto conjunto de normas - não permite a nenhum idoso a plena compreensão da sua importância no seio de uma sociedade.

Acredito que de nada nos adianta falar a respeito de como a Ética surgiu, qual o seu objeto de estudo, como ela se orienta para ação, se nada disso puder ser utilizado para o propósito de mostrar como implicar a responsabilidade ética do profissional no desempenhar das suas atividades. Muitas obras voltadas para a Ética profissional, preocupadas em demonstrar erudição, com referências inúmeras aos escritos de Aristóteles, Kant e tantos outros pensadores, esquecem-se de trazer aos olhos dos seus leitores considerações sobre uma pergunta muito simples: De que forma essa Ética, que é a do profissional que pretendo ser, diz respeito a mim enquanto pessoa?

Uma pergunta como essa é muito fácil de ser formulada por qualquer um que se depare com um "Código de Ética" de uma classe profissional qualquer. No geral, os "Códigos de Ética" buscam: i) delimitar um conjunto de ações tidas como valiosas pela comunidade profissional na qual se insere (geralmente colocados na forma de deveres); ii) elencar certos direitos e prerrogativas próprios da classe profissional na qual está inserido; iii) estabelecer critérios e procedimentos para a instituição de "Tribunais de Ética", responsáveis pela

\footnotetext{
*Professor Assistente da Universidade Estadual do Piauí. Contato: leosardeiro@yahoo.com.br Problemata: R. Intern. Fil. v. 8. n. 3 (2017), p. 258-265 ISSN 2236-8612 doi:http://dx.doi.org/10.7443/problemata.v8i3.35733
} 
apuração de fatos e responsabilização de atos transgressores das normas instituídas pelo "Código de Ética". Essa estrutura básica, efetuados alguns ajustes, deve poder ser aplicada a grande maioria dos Códigos de Ética em vigor hoje.

No entanto, um "Código de Ética" não passa de um conjunto de normas que prescrevem ações e não dão a perceber - nem mesmo minimamente - de que forma implica a "Ética" que traz no seu nome e o justifica. Todos podem aceitar que o Direito - enquanto conjunto de normas - não é algo facilmente identificado com a "Ética". Hans Kelsen, grande jurista alemão do século XX, é um dos que conseguem efetuar tal identificação, mas somente após demonstrar que qualquer tipo de norma é - em si - uma norma do tipo ético. Por que seria fácil compreender como "Ética" algo que se constitui - tal como um Código legal qualquer - por um sistema de normas prescritivas?

Penso que seja de extrema relevância discutir um pouco essa compreensão de "Ética" que acompanha os códigos de Ética e vou mais além: pretendo mostrar como o verdadeiro fundamento para qualquer tipo de pensamento Ético deve ser buscado nos sujeitos implicados, mesmo quando as determinações Éticas se impõem na forma de Código.

Acredito que qualquer Código de Ética que se queira não poderia jamais apresentar essa feição do pensamento Ético, pois que não é o seu papel. É na construção dessa feição teórica do agir de um sujeito que a "Ética Profissional" perde lugar para algo mais importante, o que chamarei aqui de "Ética do Profissional". A sua busca é compreender como O profissional deve se perceber enredado pela Ética, de forma que possa ser responsável pela sua construção.

\section{I.}

Essa talvez seja uma das questões mais difíceis do pensamento Ético. Desde sempre se tentou dar uma explicação final sobre o fundamento último do agir humano. Esse questionamento pode ser encontrado desde as epopéias do período arcaico da Grécia até os escritos mais recentes acerca da Ética. Immanuel Kant, importante filósofo alemão do século XVIII, pretendia ter dado o arremate final nessas questões, ao discutir as condições a priori do agir humano e chegar à teorização de um imperativo categórico para a razão prática. Contudo, desde Nietzsche se tem colocado em questão a possibilidade de tal formalização da razão. Algumas discussões mais recentes observam o relativismo como a regra do pensar ético, colocando a questão em termos de Pluralismo Ético, tal como aparece nos escritos do jesuíta mineiro Henrique Cláudio de Lima Vaz, por exemplo. 
Uma forma bastante interessante de se compreender a importância de se implicar a "Ética do Profissional" na "Ética Profissional" talvez se dê a partir da discussão colocada por Wittgenstein em conferência intitulada "Uma leitura sobre Ética", pronunciada em Cambridge em 1930. Wittgenstein intenta discutir a possibilidade de se apresentar uma descrição do "Ético" através da linguagem. De antemão observa que há duas possibilidades de uso para a palavra "Bom". Ela pode ser utilizada de um modo relativo ou de um modo absoluto, que é o modo próprio da Ética. No seu uso relativo, encontramos expressões como "Esta é uma boa cadeira". Um enunciado dessa natureza subentende um modelo predeterminado de apreciação da cadeira, que pode ser reconduzido a um estado de coisas e perder, dessa maneira, a sua característica de juízo de valor. O enunciado "Esta é uma boa cadeira" pode ser transformado em "Esta é uma cadeira que tem um assento confortável, estabilidade quando posta no chão e uma ótima ergonomia". E por esse caminho, já não se percebe a utilização do "Bom" na construção da sentença.

No entanto, como Wittgenstein observa, essa não é a utilização de "Bom" apresentada por um enunciado Ético. Quando no seu uso absoluto, "Bom" não permite a recondução a um estado de coisas pré-determinado e põe em evidência uma má utilização da linguagem ao tentar se referir a algo que está além dos seus limites. Dessa forma, as expressões verbais que se utilizam dessa conotação absoluta - seja do "Bom" ou de qualquer outro termo que se queira - constituem tão somente nonsense, ou seja, expressões sem sentido. Ele mostra a diferença de usos quando descreve as seguintes situações: A) Num jogo de Tênis, um jogador se refere ao outro dizendo: "você jogou mal hoje". O seu interlocutor Ihe responde: "mas eu não queria mesmo jogar bem". Pronto, e nada mais há a se dizer. Agora comparemos com a outra situação descrita: B) Alguém, em um contexto qualquer, vira-se para uma pessoa e lhe diz: "Você se comportou mal hoje". A reação a uma resposta como "Eu não queria mesmo me comportar bem" não será da mesma natureza que a anterior. De imediato, a tréplica seria: "mas você deve se comportar bem".

Se, no primeiro caso, a utilização de "Bem" remete a uma expectativa determinada sobre as formas mais adequadas de jogo e sobre o desempenho habitual do jogador com o qual se tem a conversa, no segundo não há o que se referir com a mesma palavra (BEM). Isso pelo simples fato de que, ainda que se descrevessem todas as ações moralmente aceitas num contexto social qualquer e o indicassem como referência para "Bom", ainda assim não se estaria tratando de uma utilização Ética do "Bem". Esse amontoado de proposições jamais ultrapassaria o status de "amontoado de estados de coisas" e, assim, jamais chegaria a resvalar na utilização Ética de tal palavra.

Wittgenstein acredita poder descrever a experiência ética como a experiência de "espanto frente à existência do mundo". Segundo ele, não há 
como compreender "espanto" dessa forma, pois que sua utilização correta requer uma possibilidade distinta do habitual, razão do meu espanto. Ora, em não havendo a possibilidade de se vivenciar a inexistência do mundo (ou seja, como ninguém pode viver nem mesmo por um segundo a ausência do mundo no qual está inserido) esse "espanto frente à existência do mundo" é algo sem referente, que leva a uma má utilização da linguagem. E, no entanto, é uma experiência capaz de ser vivida, tal como quando me espanto frente a um cachorro enorme e digo: "é espantoso o tamanho desse cachorro". A única diferença é que posso ter experienciado cães de tamanho menor para dar razão ao meu espanto. É esse "paradoxo da Ética" que Wittgenstein pretende explorar, e é justamente esse mesmo "paradoxo" que me faz percebê-lo como imprescindível para a compreensão do que seja a "Ética do Profissional".

Tomada com um propósito de descrição racional, tal como faço com os enunciados da ciência e do conhecimento em geral, a Ética não se explica. Ela existe, apresenta o seu conjunto de valores, pressupostos e justificativas, mas nada é possível falar a seu respeito. $E$, no entanto, falamos, e, no entanto, vivemos com isso que falamos. A Ética, por esse caminho, não apresenta qualquer tipo de fundamento racional que possa ser explicado por palavras. É preciso vivê-la e senti-la. E por essa razão, nenhum Código de Ética poderia tentar nos mostrar o "fundamento último do agir humano", pois que este precisa ser percebido pelo próprio sujeito da ação. E se assumirmos esse tipo de consideração sobre a Ética como verdadeira, como devemos pensar a "Ética" colocada ao lado direito da expressão "Código de Ética"? Para tanto, será preciso trazer à tona toda a problematização acerca do agir pessoal, e de como o sujeito de uma ação qualquer justifica para si mesmo a sua ação. Isso tudo, porém, deve ser visto de um ponto de vista interior (se é que é possível esse caminho de discussão).

\section{II.}

Essa forma de ver a Ética não é nova. Diria mais: é muito antiga. É própria das formas épicas de delineamento de caracteres dos grandes heróis. Homero, quando nos narra os acontecimentos sobre a Guerra de Tróia em seu poema llíada, apresenta uma profunda discussão sobre o agir humano e em nenhum momento se refere a uma entidade teórica como o "Bem", construída discursivamente. Ser "Bom" significa ser "virtuoso" e exemplo de um valor que é somente seu.

O poema retrata os acontecimentos de uma grande guerra e por cinco momentos é possível perceber heróis distintos diante de situações em que são obrigados a tomar uma decisão que poderá implicar a sua morte e que, quando 
se percebem vacilando sobre qual partido tomar, aplicam a si mesmos a seguinte reprovação: "E por que, coração, entregares-te a tais pensamentos?".

Não se trata de questão simples, mas de uma compreensão do agir que só se justifica pela ação. Nesse contexto, o "ser Bom" está justamente em não se perder em construções teóricas sobre o que isso significaria. O único dos heróis gregos que buscava esse caminho é Odisseu, mas por isso mesmo não é digno de confiança para os seus pares. Isso significava uma única coisa para o grego antigo: o valor de um grande herói não pode ser desejado, porque não existe possibilidade de obtê-lo. Desejar ser valoroso é algo para aqueles que não o são. Os heróis que Homero retrata já trazem a expressão do seu valor, da sua virtude, na própria estruturação do seu caráter e das suas ações. A compreensão do seu agir, a compreensão desse "ser Bom" - como apresenta Nietzsche no século XIX - só transparece pela própria ação, e é no cuidar do valor desses heróis que uma sociedade se constrói.

É isso que Homero nos ensina já no século IX a.C. e que pode ser percebido nos espetáculos trágicos da Atenas do século $\mathrm{V}$ a.C. Sófocles, grande escritor de espetáculos teatrais da Grécia clássica, escreve uma tragédia intitulada "Ájax" no século V a.C. e nos mostra como um dos principais heróis do exército grego tem o seu fim. Após perceber que fora enganado pela deusa Atena e que fora ridicularizado frente a todo o acampamento grego, Ájax se sacrifica com a espada de um grande inimigo - Heitor - para mostrar como admite o seu erro e aceita o seu destino. Essa assunção da morte frente a um erro que veio a macular a sua imagem diante do povo grego é tudo o que se precisa para mostrar o valor desse grande herói e assim perpetuar o seu exemplo para a posteridade.

Perceba-se que essa é uma discussão complexa, que envolve muitas variáveis, mas que não se fecha sobre uma apreciação teórica do que seja a "Ética". No entanto, traz no seu significado mais profundo o âmago da questão Ética. No mais profundo de toda a ação de qualquer herói épico grego e no cerne da compreensão sobre o agir humano, pode-se perceber uma interrogação latente: o que devo fazer? É preciso, porém, entender esse "o que" em toda a sua profundidade, em toda a sua amplitude. Também o "devo" não pode ser tomado como uma prescrição pura e simples de uma direção a ser assumida. A verdadeira questão Ética traz a marca da indecisão e quando verdadeiramente encarada, ela traz também o desconforto de um sujeito que se encontra frente a uma infinidade de possibilidades e não descobre razões objetivas para escolher entre nenhuma delas. A verdadeira questão Ética nasce do conflito interior em busca de algo sem referente imediato.

Nesse momento da discussão, espero que se tenha percebido que o "Ético" envolvido na "Ética profissional" não tem nada que ver com as normas que estão no Código e muito menos com as normas morais de uma religião ou 
crença qualquer. O "Ético" é de foro íntimo. Ele surge da significação que o sujeito dá às suas ações. É algo que, somente na vivência do "Paradoxo da Ética" descrito por Wittgenstein, é possível atingir a sua plenitude.

É assim que Jean-Paul Sartre, filósofo francês do século $X X$, entende que "o homem está condenado a ser livre" e que Peter Singer, outro grande problematizador das questões éticas no século $X X$, defende a compreensão da Ética de um ponto de vista prático, colocado a partir das formas subjetivas de justificação das ações humanas. Do ponto de vista do existencialismo sartreano, toda essa discussão toma um caminho bastante semelhante àquele que intento defender aqui. Para Sartre, o fato de que "a existência precede a essência" reflete no homem na medida em que ele se percebe como algo que não apresenta uma direção pré-determinada de ação. O homem é somente aquilo que a si mesmo se fizer, ou seja, é necessário pensar o homem no seu agir. É por essa razão que ele se justifica e por isso que ele se constrói na diversidade das possibilidades que Ihe estão disponíveis. Antes de mais, o homem é um ser que se projeta para o futuro - e que é consciente desse projetar-se.

Tratar da "Ética do Profissional" implica pensar que não há um caminho predeterminado a seguir. Não é por agir conforme os preceitos de um Código de Ética que se faz uma conduta Ética. Não é por respeitar de forma irrefletida um conjunto de normas qualquer que se age eticamente. O vazio da "Ética Profissional" está justamente nessa necessidade que ela tem de trazer à tona a ação consciente dos sujeitos que fazem parte de um grupamento profissional qualquer, pois que, de outra forma, ela não passa de um conglomerado inerte de normas sem sentido.

No entanto, para finalizar, é importante observar como a "Ética" tem esse apelo completamente pessoal, mas não se constrói como algo personalista. Por mais que o ser humano traga em si essa dimensão que não é capaz de ser explicada e descrita com perfeição, essa dimensão que o faz especial e o diferencia de outras formas de vida, o que faz a beleza da Ética é justamente a necessidade de se assumir essas peculiaridades do agir humano em um contexto de comunidade de seres humanos. Se sou inteiramente livre para escolher um caminho de ação que me leve a concretizar uma ideia de profissional que me é cara e valiosa, devo ter sempre em mente que essa liberdade se oferece igualmente a todos os meus pares. Essa ação de escolha deve ser feita sempre pensando em um grupo maior.

É o próprio Sartre que explica a sua proposta, em seu texto intitulado "O Existencialismo é um Humanismo":

[...] o primeiro esforço do existencialismo é o de por todo homem no domínio do que ele é e de lhe atribuir a total responsabilidade da sua 
existência. E, quando dizemos que o homem é responsável por si próprio, não queremos dizer que o homem é responsável pela sua restrita individualidade, mas que é responsável por todos os homens (SARTRE, 1973, p. 12).

Também o pensamento de Peter Singer admite que a Ética não deve ser compreendida a partir de fatos éticos objetivos, mas das formas subjetivas de justificação das ações em geral. Isso, porém, não deixa de lado a exigência de que essas justificações sejam de um determinado tipo. Ainda que uma justificação subjetiva seja condição necessária para se compreender determinada ação como um "fato ético", ela não é condição suficiente para tanto. Segundo Peter Singer, no seu livro "Ética Prática":

Para serem eticamente defensáveis, é preciso demonstrar que os atos com base no interesse pessoal são compatíveis com princípios éticos de bases mais amplas, pois a noção de ética traz consigo a ideia de alguma coisa maior que o individual. Se vou defender a minha conduta em bases éticas, não posso mostrar apenas os benefícios que ela me traz. Devo reportar-me a um público maior (SINGER, 1998, p. 18).

É possível que esse caminho me leve a pensar que mesmo a bruxa malvada, ao oferecer a maça envenenada à Bela Adormecida, desempenha uma ação ética. Desde que, ao fazê-lo, a bruxa consiga justificar e defender a sua ação a partir de um horizonte Ético mais amplo, que ultrapasse o meu interesse pessoal e satisfaça o conjunto dos interesses implicados por tal ação, será também uma ação passível de ser tomada como Ética, ainda que seja vista como uma má ação quando considerada sob um padrão ético diverso daquele adotado pela Bruxa. No entanto, esse pode ser o preço a se pagar por uma consideração da Ética que não assuma valores absolutos como guia das condutas em geral. E é necessário que seja assim, para que possamos compreender que a Ética é algo que se constrói de pessoa em pessoa, pelas diversas formas como elas se relacionam em torno de interesses comuns e socialmente referenciados.

E é nesse ponto que a "Ética do Profissional" se aproxima novamente da "Ética Profissional" e fecha todo o caminho de discussão que traçamos, por um retorno ao início. O papel de uma "Ética profissional", nesse contexto específico do trabalho, seria justamente traçar as expectativas éticas de um grupamento profissional determinado. O trabalho de cada um se desenvolve em um contexto específico. Esse mesmo contexto espera do seu profissional que ele possa desenvolver todas as questões referentes à sua própria atuação de modo a respeitar um universo maior de profissionais agindo da mesma forma.

$E$ então aqui, ao retornar de uma discussão sobre o agente para uma 
discussão sobre o contexto social, chego ao final da minha exposição citando trecho da Ilíada, de Homero (Canto XVII, 83-97):

Grande aflição envolveu a alma nobre de Heitor, conturbando-a.

Pelas fileiras o olhar alongando, ao Atrida percebe atarefado em tirar a armadura vistosa de Euforbo, e este no solo, estendido, escorrendo-lhe sangue da chaga. Corta através das fileiras da frente, soltando altos gritos, em bronze fúlgido envolto, qual chama terrível de Hefesto, inextinguível. Ouviu-lhe o clamor o alto filho de Atreu. Cheio de angústia ao magnânimo peito falou deste modo:

"Pobre de mim! Se abandono estas armas soberbas e Pátroclo, que, por vingar-me, aqui jaz estendido no solo, sem vida, temo que algum dos Aqueus, ao notá-lo, de mim escarneça. Mas se os Troianos e Heitor enfrentar, por ceder à vergonha, só, como estou, é certeza ficar pela turba cercado.

O ínclito Heitor para cá traz o exército inteiro dos Troas.

Mas para que, coração, entregares-te a tais pensamentos?

\section{Referência bibliográfica}

HOMERO. Ilíada. Tradução de Carlos Alberto Nunes. Rio de Janeiro: Ediouro, 2001.

SARTRE, Jean-Paul. O existencialismo é um humanismo. Tradução e notas de Vergílio Ferreira. In: OS PENSADORES, São Paulo: Abril Cultural, 1973. v. 45, p. 7-38.

SINGER, Peter. Ética prática. 2. ed. São Paulo: Martins Fontes, 1998.

WITTGENSTEIN, Ludwig. Conferência sobre Ética. Tradução de Darlei Dall'Agnol. In: Ética e Linguagem. 3. ed. São Leopoldo: Unisinos, 2005, p. 215224. 